\title{
Spatial Components in the Use of Count Nouns Among English Speakers and Japanese Speakers of English as a Second Language
}

\section{Michael Akiyama and Nancy Williams The University of Michigan-Dearborn}

We asked 40 English speakers and 40 Japanese speakers of English as a second language (ESL) to select a singular form or plural form of a noun in a certain linguistic context (e.g., a bag of apple or apples) involving containers and food. The size of container (small vs. large) and food (small vs. large) was controlled. The size of the small containers was comparable to that of tablespoons, and the size of the large containers was comparable to that of 4quart pans. The size of small food items was comparable to that of strawberries, and the size of the large food items was comparable to that of apples. Both English speakers and Japanese ESL speakers selected the singular noun form more often than the plural noun form when a small container was paired with a large food item (e.g., a table-

\footnotetext{
Nancy Williams, Department of Behavioral Sciences.

We thank Professors Etsuko Nakayama and Nobumoto Tajima for their kind collection of data from native speakers of Japanese. We also thank Roger Loeb and Dan Swift for their helpful comments on earlier versions of the manuscript.

Correspondence concerning this article should be directed to Michael Akiyama, Department of Behavioral Sciences, The University of MichiganDearborn, 4901 Evergreen Road, Dearborn, Michigan 48128-1491 U.S.A. Internet: makiyama@umich.edu
} 
spoon of apple). Men selected the singular noun form more often than women in all contexts. These results suggest a strong influence of nonlinguistic factors on the use of linguistic rules even among ESL speakers.

Researchers have debated whether speakers of English as a second language (ESL) learn English grammatical morphemes in the same order that native speakers (NSs) do (Dulay \& Burt, 1974; Hakuta, 1986; Krashen, 1981). This debate revolves around interpreting whether the correct usage is a result of learning explicit linguistic rules or more general rules based on humans' basic cognition. The difficulty in interpretation stems from past research that has focused on the use of morphemes in obligatory contexts in which only one form is acceptable (e.g., John ate two apple or apples).

Therefore, a study focusing on the use of morphemes in a nonobligatory context where the apparent violation of correct grammatical usage is accepted would allow a clearer interpretation. Such a study might illustrate how large the individual differences are in the use of grammatical rules among NSs of English and whether ESL speakers use the rule as English NSs do.

We planned to examine a pluralization rule associated with English nouns, because the rule contrasts prescriptive grammar and descriptive grammar (Givón, 1993; Huddleston, 1984) and because cognitive factors underlying the usage of nouns have been discussed by cognitive linguists (Langacker, 1987; Wierzbicka, 1985). According to prescriptive grammar in standard reference books of English grammar (Hornby, 1974; Quirk, Greenbaum, Leech, \& Svartvik, 1985), count nouns, noncount nouns, and nouns with dual class membership are distinguished. Count nouns are nouns that typically appear after the singular article $a(n)$ or before the plural marker -(e)s. Examples include an apple, a strawberry, two plums, and three pears. Noncount nouns are those that appear without a singular article or plural markers. Examples include butter, milk, and corn. Examples of nouns with 
dual membership are cake, paper, and light. The criteria used to distinguish these three noun categories are the grammatical contexts in which nouns appear. In other words, whether a noun appears in the count noun context (with a singular article or plural marker) or the noncount context (without these markers) or both contexts determines the noun's category. This type of noun characterization is shown in most references to ESL (e.g., Maclin, 1981).

Quirk et al. (1985, p. 251) give a more specific example that noun categories are defined by the grammatical characteristics of English nouns. They state: if a noun is count, the second noun in the measure partitive noun phrase must be plural. For this reason, a bag of apples is grammatical, but a bag of apple is ungrammatical, according to prescriptive grammar.

In contrast, descriptive grammar starts with the actual use of nouns (Huddleston, 1984). If a certain expression is produced by a significant portion of native speakers, then it becomes a part of descriptive grammar. Some cognitive linguists (Jackendoff, 1991; Langacker, 1987; Pelletier, 1975; Ware, 1979; Wierzbicka, 1985) and some developmental psychologists (Carey, 1982; Macnamara, 1981) have sought explanations for actual use of count nouns and noncount nouns. They have proposed that the count and noncount distinction has a conceptual and experiential basis. According to them, some noun categories are determined by the characteristics of the objects to which the nouns refer and by the way in which humans interact with these objects.

We extend their arguments to the following example: whether it is more appropriate to say a tablespoon of apples or a tablespoon of apple. This case involves a discrepancy between the size of container indicated by the measure partitive and the size of the object measured. We conceptualize the apple in this context as having been cut or ground from an apple, and, therefore, it must be a nondiscrete entity. Thus, a tablespoon of apple should be more appropriate, despite its apparent ungrammaticality-that is, the violation of the pluralization rule of prescriptive grammar. According to our cognitive linguistic account, the appropriate 
noun form of an object depends on the relative size of the object and the container.

The use of count nouns in prescriptive grammar and descriptive grammar has direct bearing on the grammatical knowledge among English NSs and ESL speakers. Although descriptive grammar is part of NSs' linguistic knowledge, prescriptive grammar may be the only knowledge among ESL speakers. As Givón (1993) and Huddleston (1984) have argued, prescriptive grammar is taught to NSs in formal education programs such as language arts. Although prescriptive grammar is taught to English NSs formally, over time, it becomes a small part of their knowledge. When ESL speakers are taught English formally, they are tested on rules of prescriptive grammar and their errors are corrected (Krashen, 1981). This tendency is particularly pronounced when they do not hear NSs talk.

In two studies reported in this article, we examined the effects of object size, container size, sex, and language group. If English NSs use prescriptive grammar, we should expect nonsignificant effects of object size, container size, and sex within a language group, because these variables are nonlinguistic in nature and thus have nothing to do with the grammatical use of English nouns. If, however, the NSs take nonlinguistic factors into account, we should expect some significant effects of these three nonlinguistic variables. Our main prediction is that the pattern of violation among NSs depends on the relative size of food and container. In contrast, Japanese ESL speakers who are taught English prescriptive grammar should disregard nonlinguistic factors, such as object size and container size, and follow the pluralization rule in the measure partitive phrase. We should expect a nonsignificant interaction effect of object size and container size. We should note here, however, that there is no count and noncount distinction in the Japanese language and nouns are not usually marked with respect to number (Kuno, 1973). Thus, the effect of the first language is minimized in the present study. 


\section{Study 1}

We asked 40 American college students to select the count form or noncount form of a noun in 60 measure partitive noun phrases. All of the nouns used were count nouns that refer to familiar food. Thus, the selection of the noncount form over the count form represents a shift from the count category to the noncount category.

\section{Method}

Participants. Twenty female and 20 male college students at a midwestern university participated in Study 1. They were all English NSs who were enrolled in an introductory psychology course that required participation in psychological research.

Materials. We constructed 60 measure partitive noun phrases that associate different sized containers with different sized food items. The structure of the materials is shown in Table 1. Each of 6 containers was associated with 5 small food items and 5 large food items. Fifteen small items were paired with small containers

Table 1

Foods and Containers Used in the 60 Noun Partitive Phrases

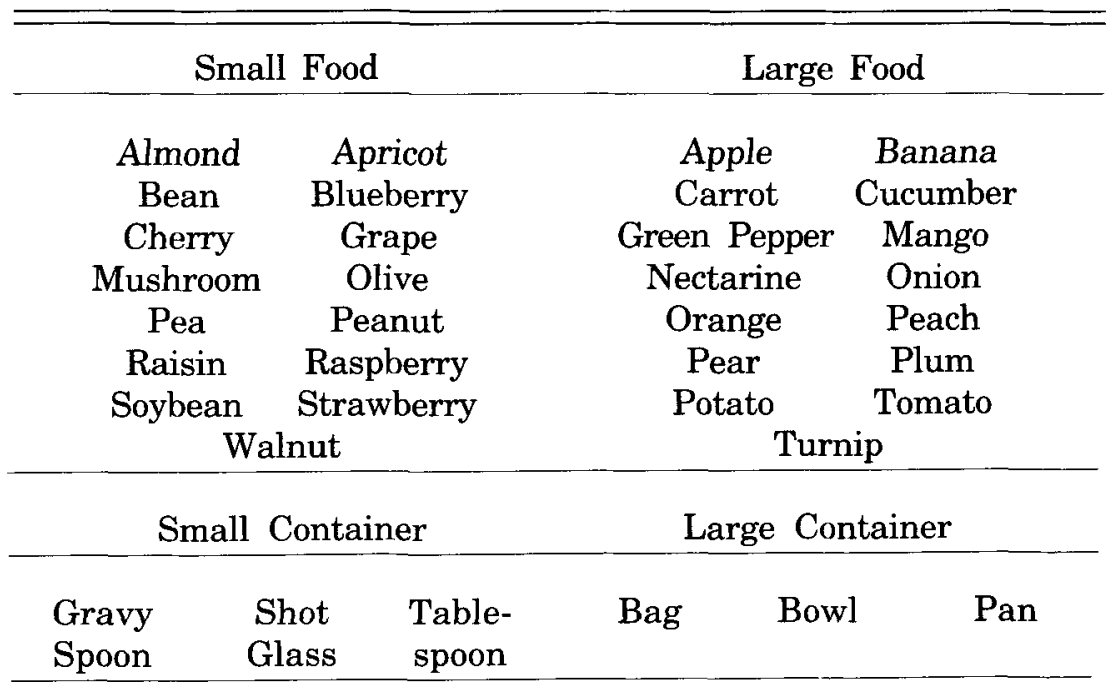


(e.g., strawberry-gravy spoon), 15 small items with large containers (e.g., pea-bowl), 15 large items with small containers (e.g., tomato-shotglass), and 15 large items with large containers (e.g., onion-pan). The participants' task was to select the count form or the noncount form in each noun phrase.

Design. We used a $2 \times 2 \times 2$ (small vs. large food $\times$ small vs. large container $\times$ female vs. male) factorial design. Food size and container size were within-subject variables. The dependent variable was the number of cases in which the noncount form was selected over the count form.

Procedure. We instructed the participants to "imagine a situation where you tell a friend the amount of cooking ingredients needed to prepare a certain dish. The following is a list of phrases that refer to various amounts of different ingredients. Please circle the expression in parenthesis that you would more frequently use." The 2 alternative expressions in each parenthesis were the count form with the plural marker and the noncount form without a marker. The order of presentation of the 60 noun phrases was random, and we gave the same random list to all the participants.

Results

The proportion of the use of the noncount noun (i.e., singular) form is shown in Figure 1. We performed a $2 \times 2 \times 2$ ANOVA. A twoway interaction of food size and container size was statistically significant $-F(1,38)=54.11, p<.01$-and a three-way interaction of food size by container size by sex was significant- $F(1,38)=$ $4.73, p<.05$, indicating that men violated the pluralization rule more frequently than women, particularly when a large food item was paired with a small container. The main effects of food size, container size, and sex were also significant- $F(1,38)=55.47$, $p<.01 ; F(1,38)=138.96, p<.01 ; F(1,38)=4.12, p<.05$, respectively. About half the participants preferred to use the noncount form in the condition of a large food item paired with a small container (e.g., a tablespoon of apple). Clearly, the participants were taking 


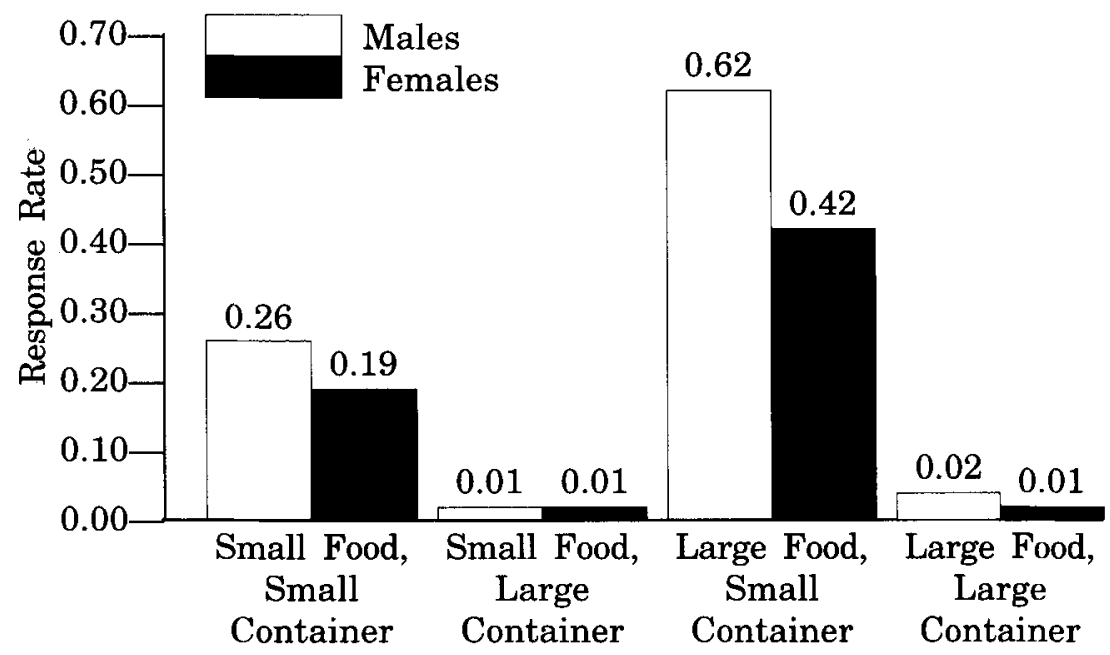

Figure 1. The proportion of singular noncount noun use by food size, container size, and sex among native speakers of English.

the relative size of food and containers into consideration; they did not strictly follow the rule of prescriptive grammar. English NSs found both singular and plural forms of nouns acceptable in a certain context.

\section{Study 2}

We designed the second study to examine whether the same effects would be found among Japanese-speaking college students enrolled in an English as a second language (ESL) program. According to Sturman (1992), the curriculum of formal education of English in Japan is largely determined by the Ministry of Education. Their curriculum emphasizes grammar. Because these ESL speakers in formal education learn the rules prescribed by traditional linguists, they serve as ideal candidates to test the prescriptive use of count nouns. If they use the pluralization rule in a measure partitive noun phrases, we should expect a nonsignificant main effect of object size and container size, and a nonsignificant interaction effect of these two variables. All of 
their responses should be the selection of count noun form based upon the pluralization rule. At the same time, they may violate the pluralization rule like English NSs. If they violate the rule, we should expect a significant interaction effect of container size and food size.

\section{Method}

Participants. Twenty male college students and 20 female college students from two different colleges participated in Study 2. One college is located in Tokyo and the other in Osaka, Japan.

Materials. In addition to the count noun test, we constructed a short vocabulary test to assess the speakers' English knowledge. The items came from various sources such as test preparation books for the Secondary School Admission Test (SSAT). The test consisted of the following 17 items: brave, erase, prestige, apprehend, amorous, abduct, menace, frugal, redundant, sober, trespass, trauma, adapt, affluent, bountiful, collaborate, and contrary.

Procedure. We handed a testing set consisting of a count noun test and a vocabulary test to students in a regular language class. The students read the instructions and circled the items they thought appropriate.

\section{Results}

The mean score of the vocabulary test was 8.37 with a standard deviation of 3.44 , indicating that the participants had sure knowledge of the meaning of half of the 17 words listed above. The proportion of the use of the noncount noun form is shown in Figure 2 . We performed a $2 \times 2 \times 2$ ANOVA. A two-way interaction of food size and container size was statistically significant- $F(1$, $38)=54.11, p<.01$, indicating that people violate the pluralization rule more frequently when large food is paired with a small container than when it is paired with a large container. The main effects of food size and container size were also significant- $F(1$, 


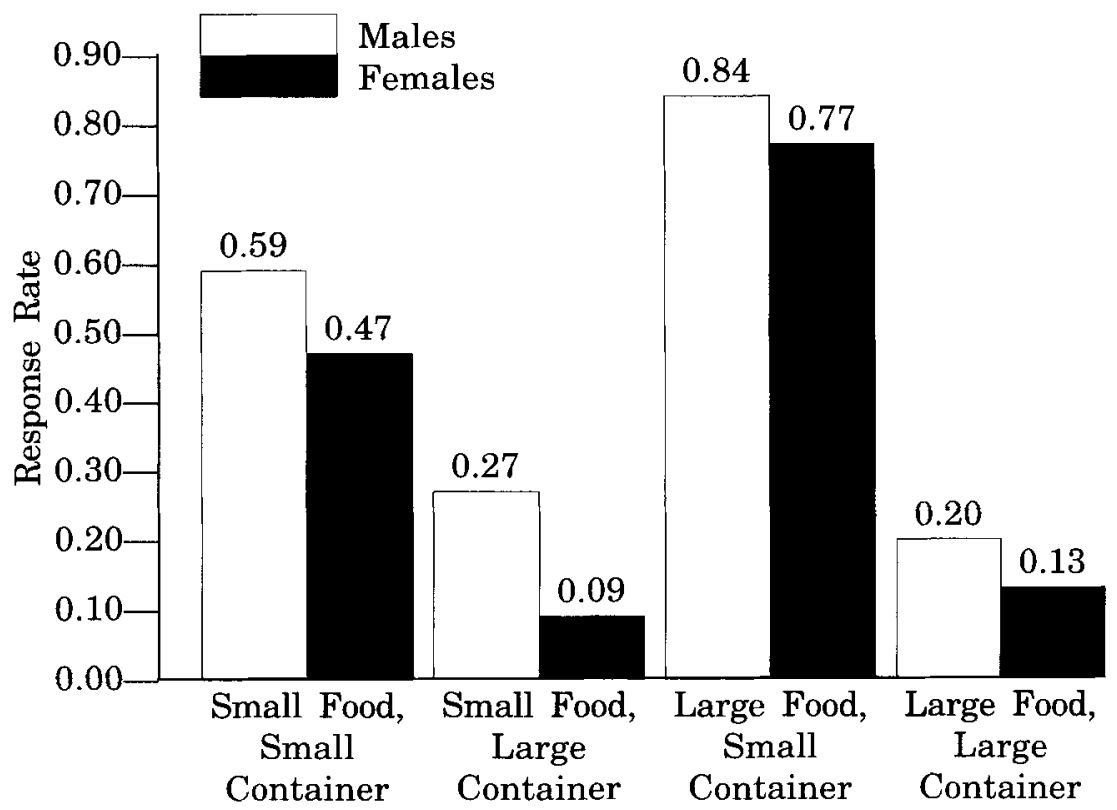

Figure 2. The proportion of singular noncount noun use by food size, container size, and sex among Japanese speakers of English as a second language.

$34)=14.37, p<.01$ and $F(1,34)=168.86, p<.01$, respectively. The main effect of sex was marginally significant $-F(1,34)=4.01$, $p<.06$. The other interaction effects were not significant. The correlation between the vocabulary test scores and the number of singular forms in the measure partitive noun phrase under the condition of large objects in small containers was -.17 and was not significant.

\section{Discussion}

The strongest pattern to emerge is that English NSs tend to violate the traditional linguistic rule in a certain context. The context in which violations occur most frequently is when a large object (e.g., an apple) is paired with a small container (e.g., tablespoon). In this context, English NSs tend not to use the 
plural form of the noun that refers to a large object, despite its grammaticality.

Speakers of ESL, who should follow the linguistic rule explicitly taught to them, also violate the pluralization rule in the context of a small container paired with a large food item. They violate the rule despite their weak performance on the English vocabulary test (indicating limited proficiency in English) and despite their clear knowledge of the rule in other contexts. This pattern is similar to the pattern of English NSs.

That half of the English NSs used the plural form while the remainder used the singular form suggests that both forms are acceptable in terms of descriptive grammar of the English language. In addition, ESL speakers who had been taught English grammar formally showed a similar pattern. These results point to a common rule suggesting that both groups pay attention to the relative size of food and container.

The common rule may have something to do with the spatial impossibility of a small container enclosing a large object. While deciding on the singular or plural form of apple in the context of a tablespoon of _ _ for example, people conceptualize how they can put the plural number of apples into a tablespoon. When they think that the size of the tablespoon is too small to accommodate the apples, they select the singular form. Because most people in the present study selected the grammatically correct form in those contexts involving no spatial impossibility, the relative size of food and container emerges as a definite factor influencing the selection of an appropriate noun form. ${ }^{1}$

These hypothesized processes may be tested in future studies by asking people to describe a scene while timing them. People may describe a scene of several food items in a container more quickly than that of an item in a container too small for it. This research design would eliminate a subjective factor as to what size of food they imagined and would provide a precise measurement of their language behavior.

Our results on the use of nouns among ESL speakers are comparable to those results from a recent study on the use of 
definite and indefinite articles by ESL learners (Thomas, 1989). Thomas demonstrated that Chinese and Japanese ESL speakers tended to show errors similar to errors made by children acquiring English as their native language. These speakers, except the most advanced, used nouns without an article more than $20 \%$ of the time when indefinite articles or definite articles were required. The pattern of errors by low, mid, and high levels of speakers closely corresponded to the errors made by children acquiring their first language. The ESL speakers in Thomas' study used the singular form without an article about $20 \%$ of the time in conditions where NSs rarely used the singular form. Otherwise, the use of singular forms was similar across the two language groups.

A strong gender effect in the English NSs and a marginal effect of gender in the ESL speakers may strengthen the interpretation that spatial impossibility and linguistic rule are weighed against each other. Female superiority in language use and male superiority in spatial relations are well documented (Coates, 1993; Halpern, 1992; Maccoby \& Jacklin, 1974; Sanders, Soares, \& D'Aquila, 1982; Sherman, 1967). Males show a stronger tendency to violate linguistic rules on the basis of their understanding of spatial impossibility; females tend to adhere to traditional linguistic rules despite spatial impossibility.

All these results showing the effects of nonlinguistic factors on the selection of noun forms support cognitive linguistic accounts (Jackendoff, 1991; Langaker, 1987; Pelletier, 1975; Ware, 1975; Wierzbicka, 1985). When linguistic rules allow some flexibility, people speaking different languages appear to maximize the flexibility through conceptualization. Commonly observed errors such as less calories (calorie is a count noun) and confusion over the use of much and many (Gathercole, 1985) can be similarly interpreted. The concept of calories, unlike that of apples, is abstract and practically implies an amount rather than quantities. Thus, the quantifier less rather than fewer is used with the unit of calories. If these expressions are used by a significant portion of English NSs, they should be acceptable in descriptive grammar of the English language. 
Our results also support the language universal hypothesis proposed by Dulay and Burt (1974) and Hakuta (1986). Although morpheme studies in obligatory contexts are problematic (Long \& Sato, 1984), our study addressed a nonlinguistic force that might operate in second language (L2) learning. Unlike the linguistic account (Dulay \& Burt, 1974; Hakuta, 1986), we suggest a spatial factor that could produce commonality in L2 learning. Perhaps, ESL speakers might show similar errors on our task despite their first-language background.

The use of the two noun categories demonstrated here may extend knowledge of the acquisition of noun categories. As Macnamara (1981) argued, children acquiring count and mass nouns could base their judgment on either semantic features or syntactic features. The syntactic feature hypothesis may be supported by the fact that children start distinguishing these two noun categories-that is, using noun forms in appropriate syntactic contexts-at the age of two-and-a-half (Gordon, 1985, 1988; Mervis \& Johnson, 1991). In contrast, the semantic feature hypothesis may be supported by the fact that young children can discriminate objects from substances even before they start speaking (Soja, Carey, \& Spelke, 1991) or by the finding that $75 \%$ of the children in McPherson's (1991) study used perceptual cues about individuation regardless of syntactic cues given to guide their responses.

The conflict in usage between the two noun categories continues beyond childhood and across language groups. Given the spatial impossibility of enclosing a large item in a small container, adult English NSs, particularly adult males, tend to violate the linguistic rule that requires the count form of nouns in measure partitive phrases. The same, though weaker, tendency pertains among Japanese ESL speakers. All adult speakers in the present study tended to use the noncount form of nouns in a situation in which small containers enclosed objects larger than themselves. This tendency is cross-linguistic and perhaps is universal across different language groups of ESL speakers.

In conclusion, we have shown that people's selection of noun 
forms in a measure partitive noun phrase (e.g., a tablespoon of __ is influenced by nonlinguistic factors, such as their gender and the food size relative to container size. These nonlinguistic factors are independent of an individual's language background. Both English NSs and Japanese ESL speakers prefer to use a singular noun form when large food is associated with small containers. These results suggest that nonlinguistic factors operate in the use of language among NSs as well as L2 learners.

Revised version accepted 8 November 1995

\section{Note}

${ }^{1}$ An anecdotal report from a participant whom we tested in an informal setting may support the above hypothesis. She stated that she visualized an apple and a tablespoon and realized that the apple would not fit into the tablespoon. However, in completing the phrase, she knew the linguistic rule and applied it rather than the spatial impossibility she had visualized.

\section{References}

Carey, S. (1982). Semantic development: State of the art. In E. Wanner \& L. R. Gleitman (Eds.), Language acquisition: The state of the art (pp. 347389). Cambridge: Cambridge University Press.

Coates, J. (1993). Women, men, and language: A sociolinguistic account of gender differences in language (2nd ed.) London: Longman.

Dulay, H. C., \& Burt, M. K. (1974). Natural sequences in child second language acquisition. Language Learning, 24, 37-53.

Gathercole, V. C. (1985). "He has too much hard questions": The acquisition of the linguistic mass-count distinction in "much" and "many." Journal of Child Language, 12, 395-415.

Givón, T. (1993). English grammar: A function-based introduction. Amsterdam: Benjamins.

Gordon, P. (1985). Evaluating the semantic categories hypothesis: The case of the mass/count distinction. Cognition, 20, 209-242.

Gordon, P. (1988). Count/mass category acquisition: Distributional distinction in children's speech. Journal of Child Language, 15, 109-128.

Hakuta, K. (1986). Mirror of language: The debate on bilingualism. New York: Basic Books.

Halpern, D. F. (1992). Sex differences in cognitive abilities (2nd ed.). Hillsdale, NJ: Erlbaum. 
Hornby, A. S. (1974). Oxford advanced learner's dictionary of current English (3rd ed.). London: Oxford University Press.

Huddleston R. D. (1984). Introduction to the grammar of English. Cambridge: Cambridge University Press.

Jackendoff, R. (1991). Parts and boundaries. Cognition, 41, 9-45.

Krashen, S. D. (1981). Second language acquisition and second language learning. Oxford: Pergamon Press.

Kuno, S. (1973). The structure of the Japanese language. Cambridge, MA: MIT Press.

Langacker, R. W. (1987). Foundations of cognitive grammar: Vol. I. Theoretical prerequisites. Stanford: Stanford University Press.

Long, M. H., \& Sato, C. J. (1984). Methodological issues in interlanguage studies: An interactionist perspective. In A. Davies, C. Criper, \& A. P. R. Howatt (Eds.), Interlanguage (pp. 253-279). Edinburgh: Edinburgh University Press.

Maccoby, E. E., \& Jacklin, C. N. (1974). The psychology of sex differences. Stanford, CA: Stanford University Press.

Maclin, A. (1981). Reference guide to English: A handbook of English as a second language. New York: Holt, Rinehart, and Winston.

Macnamara, J. T. (1981). Names for things: A study of human learning. Cambridge, MA: MIT Press.

McPherson, L. M. P. (1991). A little goes a long way: Evidence for a perceptual basis of learning for the noun categories count and mass. Journal of Child Language, 18, 315-338.

Mervis, C. B., \& Johnson, K. E. (1991). Acquisition of the plural morpheme: A case study. Developmental Psychology, 27, 222-235.

Pelletier, F. J. (1975). Non-singular reference: Some preliminaries. Philosophia, 5, 451-465.

Quirk, R., Greenbaum, S., Leech, G., \& Svartvik, J. (1985). A comprehensive grammar of the English language. London: Longman.

Sanders, B., Soares, M. P., \& D'Aquila, J. M. (1982). The sex differences on one test of spatial visualization: A nontrivial difference. Child Development, 53, 1106-1110.

Sherman, J. A. (1967). Problem of sex differences in space perception and aspects of intellectual functioning. Psychological Review, 74, 290-299.

Soja, N. N., Carey, S., \& Spelke, E. S. (1991). Ontological categories guide young children's inductions of word meaning: Object terms and substance terms. Cognition, 38, 179-211.

Sturman, P. (1992). Teamteaching: A case study from Japan. In D. Nunan (Ed.), Collaborative language learning and teaching (pp. 141-161). Cambridge: Cambridge University Press. 
Thomas, M. (1989). The acquisition of English articles by first- and secondlanguage learners. Applied Psycholinguistics, 10, 335-355.

Ware, R. (1975). Some bits and pieces. Synthese, 31, 379-393.

Wierzbicka, A. (1985). "Oats" and "wheat": The fallacy of arbitrariness. In J. Haiman (Ed.), Iconicity in syntax: Proceedings of a symposium on iconicity in syntax, Stanford, June 24-26, 1983 (pp. 311-342). Amsterdam: Benjamins. 